\title{
Increasing Student Attendance at Library Workshops: What the Data Tells Us
}

\section{Richelle L. Witherspoon and Philip O.L. Taber}

\begin{abstract}
With attendance rates at library workshops and events in decline, the authors looked to data from practice to help the field move forward. Using survey responses from providers of 161 library workshops across Canada and the United States, the authors examined 10 key variables that are widely believed to impact attendance rates (topic, month, time, duration, advertising, location, target audience, series status, buy-in, and incentives). Analysis of the responses highlights several trends in attendance and offers a better understanding of what students are looking for from extracurricular educational opportunities like those provided by libraries.
\end{abstract}

Many academic libraries struggle with student attendance at workshops, particularly workshops that are not mandatory. ${ }^{1}$ It can be unclear what draws students to a workshop and which factors impact their attendance. In some cases, attendance rates may decline after a period of relative success. In other cases, attendance is a challenge from the first time a workshop is offered. Various remedies have been proposed for these problems both within institutions and in the broader library literature. However, there is little evidence in the literature to support the success of one tactic over another. This paper uses data from current practice to identify which factors meaningfully boost student attendance and which do not.

Although it is difficult to assess the impact of library instruction and student-targeted workshops on overall student success, there have been studies that have shown a relationship between these efforts and measures of success like student retention and grades. Bowles-Terry ${ }^{2}$ found higher GPAs in graduating students who had library instruction in upper-level courses. Vance, Kirk, and Gardner ${ }^{3}$ also found a positive GPA correlation, though they did not identify an effect on retention. In a 2016 longitudinal study, Rosman, Mayer, and Krampen ${ }^{4}$ found that information literacy instruction had a significant impact on the development of informationseeking knowledge, even when controlling for a range of other cognitive factors. A large study in 2017 by Blake et al. ${ }^{5}$ examined 42,000 first-year students from 1,700 courses in 12 research institutions, concluding that retention, GPA, and course credits completed per year were all higher on average for students who received information literacy instruction. Marineo and $\mathrm{Shi}^{6}$ found that research assignment grades and library use sessions, together, are predictors of higher GPA and one-year retention. Other studies, such as Webster and Rielly, ${ }^{7}$ note a weak

\footnotetext{
${ }^{*}$ Richelle L. Witherspoon is Information Services Librarian in the Harriet Irving Library at the University of New Brunswick; email: rwithers@unb.ca. Philip O.L. Taber is a librarian in the Hans W. Klohn Commons at the University of New Brunswick; email: philip.taber@unb.ca. @2021 Richelle L. Witherspoon and Philip O.L. Taber, Attribution-NonCommercial (https://creativecommons.org/licenses/by-nc/4.0/) CC BY-NC.
} 
positive correlation with workshop attendance and individual assignments but do not address macro-level definitions of success such as GPA.

The existing literature is divided between studies examining mandatory (usually courseembedded) library instruction programs ${ }^{8}$ and studies examining optional workshop programs, ${ }^{9}$ but both the mandatory and the optional approaches seem to improve students' information literacy skills. The single study that compares separate workshops and course-embedded instruction ${ }^{10}$ suggests that more mandatory, embedded instruction yields larger improvements in students' ability, but a direct comparison between approaches may be complicated by selection bias; mature students ${ }^{11}$ and more highly motivated students ${ }^{12}$ may be more likely to seek out optional supports, so correlation between student improvement and optional workshop attendance could be mediated and/or attenuated by that bias. Regardless of selection biases, mandatory vs. optional workshops, and the specifics of outcome type, it is clear from the literature that exposure to information literacy instruction is strongly correlated with improved student outcomes. All this evidence supporting the value of academic workshops underscores the importance of attracting students to those workshops, but how can that be accomplished?

The answer to this question is a difficult one, as students have varying and contradictory perceptions of nonmandatory workshops. Writing about a student support program in Indiana, Berumen, Zerquera, and Smith ${ }^{13}$ report that students "who did not take advantage of [support] services also understood their value. Several reported regret for failing to take advantage of the support offered to them." A similar case is described by Booth et al. ${ }^{14}$ reporting on a focus group made up of college students. During their discussions, students had "frequently stated that having both academic and extracurricular engagement was critical to realizing their success" but felt that their peers may "not necessarily understand the value and importance of engagement" and should "be more proactive" in attending optional courses and sessions.

Berumen et al. ${ }^{15}$ and Booth et al., ${ }^{16}$ then, appear to show a generally positive student opinion of support services, which complements the evidence by researchers like Blake et al. ${ }^{17}$ showing that information literacy instruction correlates positively with GPA, retention, and course completion. Despite this finding, however, libraries and other academic support units struggle to turn positive opinion into action. Of the workshops polled in the present study, which consisted of workshops offered by libraries (95\%) as well as other academic support units like math help centres and study skills centres, 42 percent had fewer than 5 students in attendance. Many had no students attend at all. The unfortunate fact of the matter is that students simply do not show up to optional workshops in any significant numbers. Even when the pressure is on, and students are tested on a skill by their course instructors and know they need to develop it, attendance rates even at targeted sessions remain low. ${ }^{18}$ This persistent and frustrating issue brings us to the crux of the matter.

Academic support workshops must have qualities that may make some more or less desirable to potential attendees. Workshop providers carefully consider such things as day, time, physical space, and topic but have little evidence to support which decision is most likely to maximize attendance. While a number of studies have explored the preferences of students with respect to these and other factors, ${ }^{19}$ they did not address the effect that accommodating student preferences had on attendance rates. At the same time, multiple studies suggest that students are poor predictors of their own attendance-related behaviour, expressing their interest in attending a workshop, or even their intent to attend, but then not actually going. In one study, Cheng and Johnston ${ }^{20}$ note that "students who attended only one session nonetheless 
reported on their survey that they would be very likely to attend another session" and then did not follow through. Another study, by Critz et al. ${ }^{21}$ described the issue of high registration rates for library sessions (which might be considered an analog to interest or intent) but low actual attendance rates. This tendency of students not to behave according to their own stated preferences and intentions suggests that approaching them about ways to improve attendance rates at workshops would be ineffective. Approaching librarians for ideas would be similarly ineffective, because if librarians as individuals had the answer to this issue, we would not be grappling with it. Given this, the best way to understand what it is that makes one workshop better attended than another seemed to be looking at the workshops themselves and considering their success rates alongside factors that have been posited to influence those rates, such as time of day, topic, duration, and advertising type. By doing a survey of workshop providers and asking questions about a specific workshop they had hosted, we were able to address the issue of attendance rates from a practical perspective and answer the question: in practice, what workshop characteristics have already resulted in higher student attendance rates? And, consequently, what actions can workshop providers take to increase student attendance when planning their workshops?

\section{Methods}

This study targeted providers of nonmandatory academic support workshops at universities and colleges. These workshop providers consisted largely of librarians, but they also included other library staff and staff from writing, study, and math centres. Participation was restricted to individuals working in Canada and the United States and required participants to be English speakers, as the survey was distributed in that language only.

For the purposes of this study, workshops were described as:

“any optional, class-like offering provided by a nonprofessor/instructor (such as a librarian, library staff, or staff member at a writing or math help centre) outside of course hours for the purpose of providing academic support. For example, a non-mandatory workshop might be a session on plagiarism, a workshop on GIS software, or a talk about scholarly publishing. Nonmandatory workshops do not include anything offered by a teaching assistant for the purposes of a specific course, and do not include any sessions targeted solely at faculty and staff (mixed target audiences welcome)."

A two-phase approach was implemented for this study.

For phase one, 42 participants were recruited using a number of academic listservs targeted at librarians and other academic support professionals. The listservs contacted were the Canadian Association of Professional Academic Libraries list (twice), the Canadian Association of College and University Student Services (once), and the American Library Association's ILI-L list (twice). These participants completed a survey in which they were asked to thoroughly report details about the context of one particular workshop they had hosted. The survey was developed by looking at the literature and highlighting the factors that are most commonly (whether erroneously or not) associated with workshop attendance rates. Some additional questions pertaining to controllable factors that are decided upon during the development of a workshop were also included in the survey. The questions in the survey were 
a combination of multiple choice and open-ended, and the survey as a whole took between 10 and 15 minutes to complete.

Results from the first survey were compiled and assessed. This data was then used to develop a second, shorter survey (see appendix A) that focused on the factors that tended to vary the most between workshops in the first survey, eliminated factors that were not implemented, and condensed more questions into multiple-choice format. This approach allowed us to shorten the time the survey took to complete to roughly 6 to 8 minutes. The data from Phase 1 was then coded appropriately for analysis with responses from this new survey. Because the survey in Phase 2 was created based on the findings in the first survey and was specifically designed to allow it to capture the same information in a clearer and more discrete format, the inclusion of Phase 1 data in Phase 2 was straightforward. Data recoding was performed by one author and consisted almost exclusively of unambiguous coding decisions; in cases where coding ambiguity existed, the data was considered lost and was not included for analysis. The new survey was implemented in Phase 2.

Phase 2 included 363 participants (in addition to the 42 participants from Phase 1 ) who were recruited using the same approach used in Phase 1, except that the survey had been shortened, and potential participants were also incentivized with a 1/100 chance to win a \$76 USD (\$100 CAD) gift card to one of several popular stores/restaurants upon completion of the survey. The listservs contacted for Phase 2 were the Canadian Association of Professional Academic Libraries (3 times), the Atlantic Provinces Library Association (twice), the American Libraries Association ILI-L listserv (4 times), and the Canadian Medical Libraries list (once). Results from the second survey (including the recoded responses to the first) were compiled, and 10 factors that arose from the data were analyzed for their effect on the probability of success of a workshop. Those factors were topic, duration, month of the term/semester, time of day, session location, target audience, series status, faculty/departmental buy-in, type of advertising, and incentive and were all considered against the dependent variable of workshop success:

Workshop success: the authors deemed a workshop to have been successful if it had five or more attendees. This number, while small, was chosen to reflect the point at which it begins to become more time efficient to host a workshop than to meet with students one on one. It also offered a reasonable threshold for success, given the overall trends in attendance rates at workshops, and respected a demonstrated preference by students for smaller workshops that offer more individual-focused pedagogy options. ${ }^{22}$ It should be noted, however, that, even when the threshold for a successful workshop was increased moderately, the pattern of the findings obtained remained relatively consistent.

Topic: nine topic categories were coded from the survey, with an additional category of "other" capturing topics that did not fit into the coding scheme. Topics coded as "other" included sessions on paleography, GIS software, civil discourse and misinformation, research poster design, and academic technologies. The nine topic categories used were academic integrity, citation management software, citing, course- or assignment-specific help, general library orientation, publishing/ scholarly communications, searching skills, specific library skill(s), writing and study skills, and other. 
Duration: session duration was coded into one of four ranges - "30 minutes or less," “30-60 minutes," “60-90 minutes," or "90 minutes or more."

Month of term: the month in which a session was held was reported and then was recoded to reflect which month in the term - first, second, third, or fourth - the session was held. Sessions that were hosted in May, June, July, and August were coded as having occurred in the summer, as most institutions have limited summer programming for which a month-of-term approach was deemed inappropriate.

Time of day: time of day was reported as a range of hours at which a session started and was reported in multiple choice format as - "Morning (before 11:00 AM)," "Midday (11:00 AM-2:00 PM)," "Afternoon (2:00 PM-5:00 PM)," or "Evening (at or after 5:00 PM)."

Session location: sessions were reported as having taken place "In the library," "In a faculty or departmental building," or "Other." "Other" locations included such places as a room adjacent to a cafeteria and a building across the street from the library. The impact of session location on workshop success can be seen in figure 2 .

Target audience: reporting options for this variable were- "All students, staff, and faculty," "All students," "All graduate students," "All undergraduate students," or a "Specific group" of students (such as international students, business students, or students writing theses).

Series status: this variable considered whether a workshop was part of a new or ongoing series of related workshops.

Faculty buy-in: a faculty or department was coded as having "bought in" to a session if they had contributed to advertising for it in some way, through mentioning it in a class or sending out an email over the departmental listserv.

Advertising type: respondents were able to choose any (or all) of seven different advertising options, including an "other" option. These options were then recoded into two types - "Push" and "Pull." For our purposes, "push" advertising was any type of advertising that was delivered directly to the target audience in some way (as through email or in-class announcement), while "pull" advertising included advertising types that relied on the target audience noticing or locating it in a more passive manner (as through LCD screen advertisements, posters, and social media). The impact of advertising type on workshop success can be seen in figure 3 .

Incentives: participants were asked if they provided any sort of incentive to attendees and, if so, respondents were given an open-ended option to describe the type of incentive that was provided. The incentives offered were recoded into three categories - "No incentive," "Academic credit," and "Food or prize." 


\section{Results}

Of the 405 surveys collected, a total of 218 surveys ( 40 from the first phase) were coded and analyzed. Surveys that were not included in the analysis were duplicates of the previous phase, were less than 50 percent complete, or failed to report the number of attendees at the workshop. Of the 218 surveys that were included in the analysis, 80 were from large institutions $(>15,000$ FTE), 64 were from medium-sized institutions (5,000-15,000 FTE), 65 were from small institutions $(<5,000 \mathrm{FTE})$, and 9 surveys did not indicate the size of the institution. Fully 95 percent of these were offered by librarians or library staff, while the remaining workshops were offered by other student academic support services (such as math help centres and study skills centres). Attendance rates across workshops ranged from zero to 85 students, with a mean of 10.17 and a median of 6 . A frequency distribution of the attendance rates is provided in figure 1.

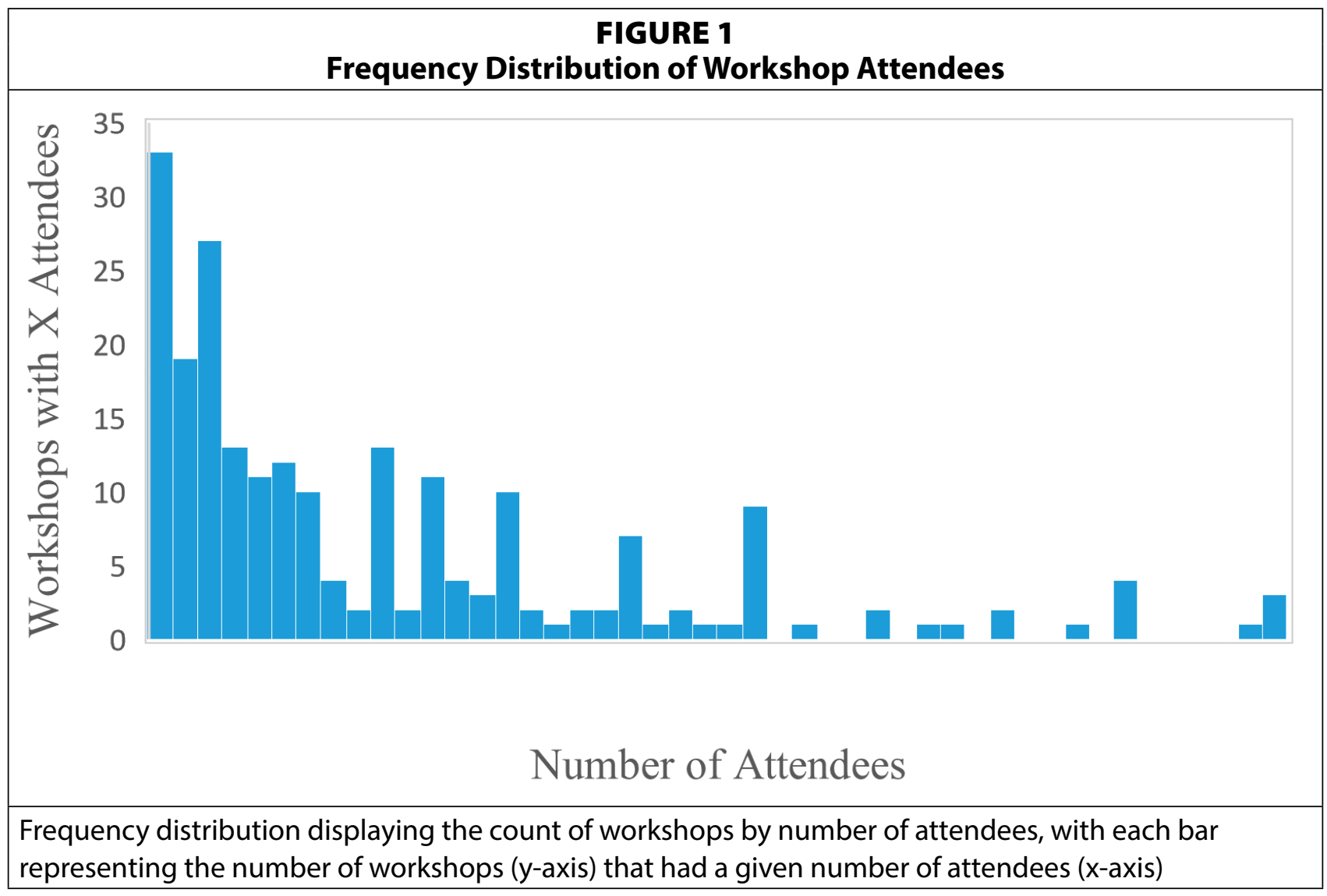

\section{Outcomes}

Overall, 58 percent of the workshops analyzed from this survey achieved the established threshold for success at five or more attendees. Chi-square tests were then performed on each of the variables to determine which had a statistically significant effect on that success rate. Of the ten factors, three were found to be significant:

1. Topic: Despite being distributed across nine categories, topic was found to significantly affect workshop success, with the adjusted residuals from the Chi-square test showing that citation management software workshops (2.1) were less often successful than the average workshop, while course/assignment-specific workshops (workshops hosted in response to specific needs generated by a course or assignment, but that were not mandatory, offered during class time, or taught by course TAs or instructors; -2.3 ) and "other" workshops (-2.0) were successful more often than average. 

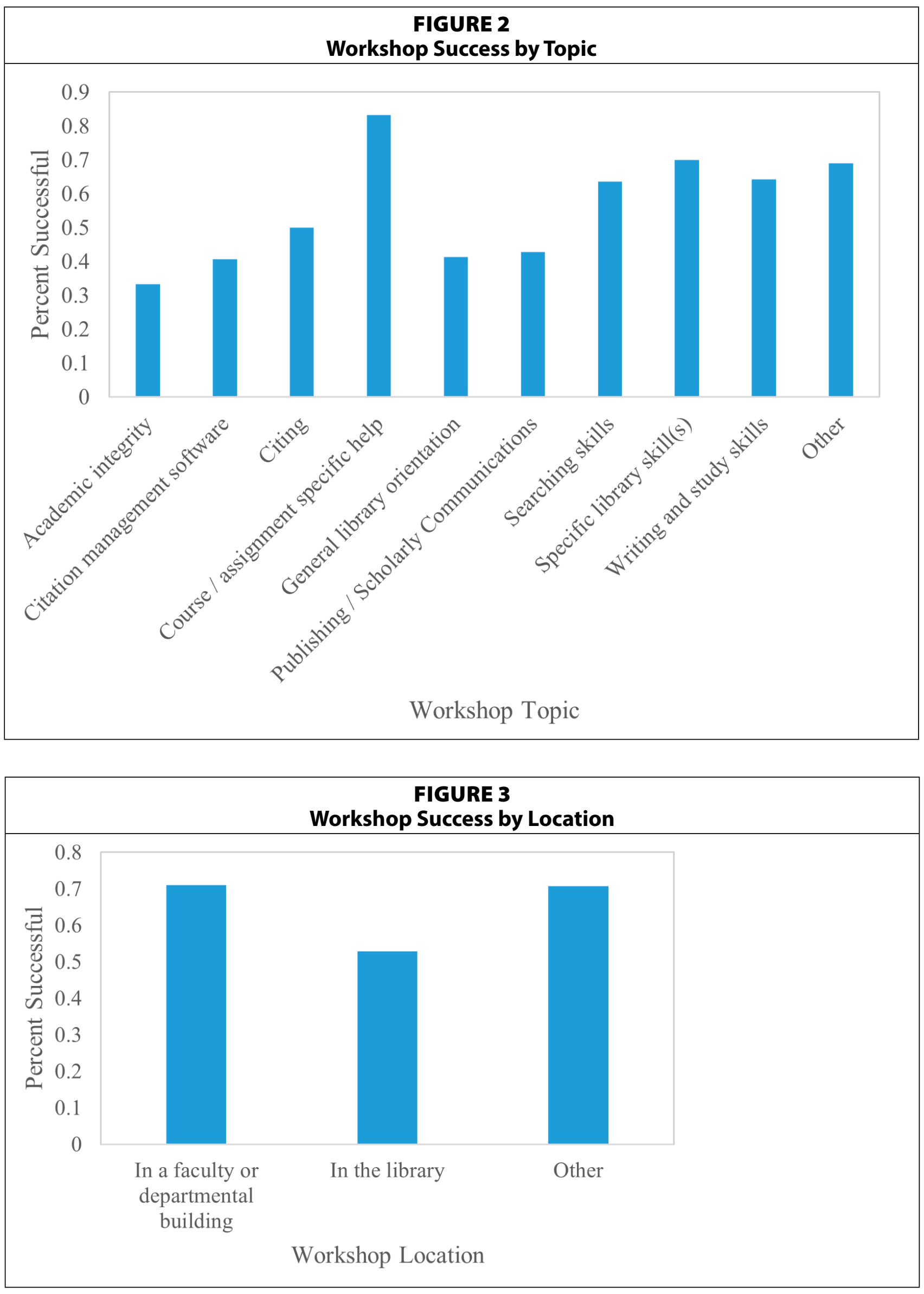


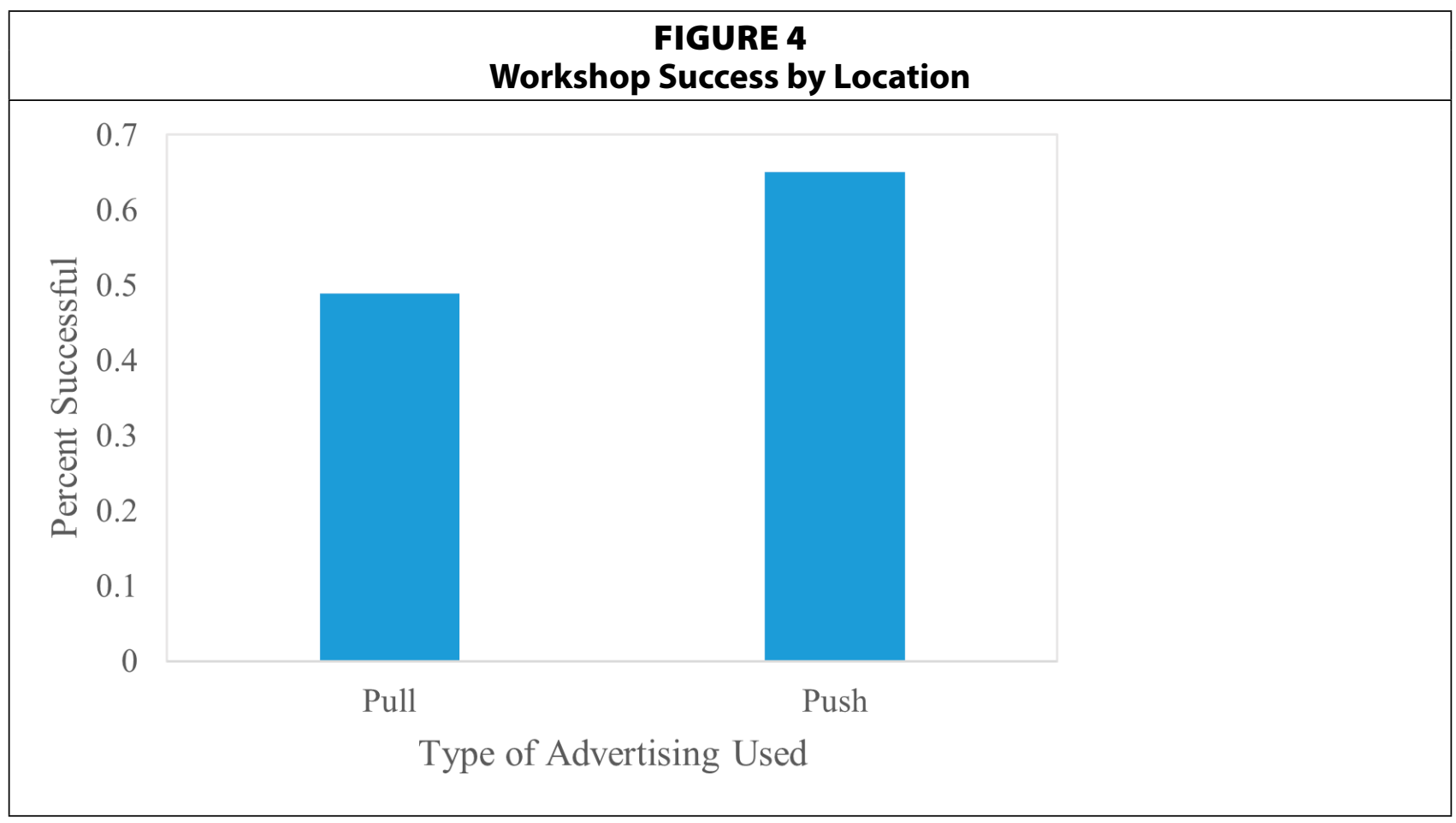

2. Session location: The location in which a session was hosted also had a significant effect on workshop success, with the adjusted residuals revealing that in-library workshops were less often successful than workshops hosted outside of the library (2.4).

3. Advertising type: Advertising type was found to have a significant effect on workshop success $\left(\chi^{2}=5.68, \mathrm{df}=1, p=0.02\right)$. Workshops that were advertised using "push" advertising were significantly more likely to have five or more attendees.

Summaries of the 7 nonsignificant variables are provided for descriptive purposes in appendix B.

In addition to analyzing the 10 main factors for overall effect, two of the factors were recoded into dichotomous variables to determine whether other effects might be present. The variables that were recoded were target audience (specific group vs. other groups) and incentives (academic credit vs. no credit or food/prizes). Following the Bonferroni adjustment that was made to the $p$-value for these additional analyses, only the target audience was found to be statistically significant, with workshops targeting specific groups yielding higher success rates than workshops targeting more general student populations $\left(\chi^{2}=8.03, \mathrm{df}=1, p=0.005\right)$.

\section{Discussion and Recommendations}

Of the factors evaluated in this study, only four were found to significantly impact workshop success: topic, session location, advertising type, and target audience. Topics that were highly targeted like course/assignment-specific workshops, and "other" topics (which included such topics as paleography, GIS software, civil discourse and misinformation, research poster design, and academic technologies) were more likely to be successful than broader topics that might have benefited a larger number of students. Sessions hosted in faculty/department buildings were preferred over those hosted in the library. Specially targeted advertising that was delivered directly to the student and did not rely on a student noticing it somewhere (be it digital or print) also correlated with workshop success, as was the targeting of a specific audience. 
Librarians, and other workshop providers, have put a great deal of time and consideration into how to attract students to their workshops, knowing from a large amount of evidence that the skills being taught in those workshops are highly beneficial to the students who acquire them. ${ }^{23}$ This study considered some of the most frequently discussed factors and found that only four had a significant impact on the success of a workshop. Even more, the impact itself is not necessarily intuitive - it was not the most broadly applicable topics, discipline-neutral locations, the larger target audiences, or advertising that reached the most people that correlated with success. Some of the most popular factors cited and discussed by librarians - time of day, shorter sessions, food or prize incentives, and month of term - were not found to be significant at all.

Instead, the findings of this study seem to suggest that what is most important to students is targetedness and specificity: students want workshops to be delivered on a topic of immediate relevance to them, be delivered in their space, be advertised directly to them, and be unique to their needs. In early stages of data collection, students also showed a strong preference for longer workshops (of 90 minutes or more) that was suggestive of a desire for deep topic coverage but, while worthy of note, that preference did not remain statistically significant as more data was collected.

The results of this study offer some information about trends in student attendance at certain workshops and the factors that can be used to maximize the likelihood of success from a perspective that had not previously been explored. Previous research has considered students perspectives, wants, and needs, ${ }^{24}$ but research has also shown that students often do not follow through on their intent to attend workshops. ${ }^{25}$ The results of this research have identified the specific factors that can be directly tied to workshop success based on what has happened in actual workshops in the past. However, this research cannot provide the full answer alone. The study looked at past trends only, and while past patterns can and should inform future decisions, the effectiveness of certain techniques may change over time. Additionally, it is possible that the effectiveness of some factors measured is more or less pronounced in practice than appeared in our sample as-despite a deliberate effort to recruit information on both successful and unsuccessful workshops - we cannot be certain that there was no bias toward reporting successes, particularly if a respondent had hosted multiple workshops and only completed the survey once.

On the other hand, it is possible that some factors that were not found to significantly impact workshop success rates may, in fact, do so. The high degree of variance in our sample, coupled with multiple response-options within each factor (like four possible responses for time of day), made it difficult to obtain statistical significance in many cases, even when working with a sample of more than 200 workshops. On a related note, it is also worth stating that, even if a workshop incorporates all of the suggestions extrapolated from this study, there is still no guarantee that it will be successful. Similarly, a workshop that fails to incorporate any of the suggestions from this research may be very well attended. The trends observed in student attendance, while robust in some cases, did not yield 100 percent success rates, and attendance varied widely on a case-by-case basis. So, while these trends can be used to inform practice, they should be considered guidelines only; they do not (by themselves) justify creating new workshops or canceling current ones. Future work on this topic should look into how these trends impact attendance when applied in a deliberate way, and the differential impact on attendance of using multiple factors in a single workshop vs. simply applying one or two. 
Even so, a series of specific actions that can be taken by workshop providers to increase success rates can be extrapolated. The four key things that are suggested by the results of this study are that workshop providers should:

1. Focus on assignment- or course-specific topics, or "other" highly specialized topics such as paleography, GIS software, civil discourse and misinformation, research poster design, and academic technologies;

2. Host sessions in nonlibrary locations, such as faculty/departmental buildings and other buildings where students tend to congregate;

3. Whenever possible, employ "push" style advertising such as email and in-class announcements;

4. Target a specific group of students, such as graduate psychology students, all international students, or first-year engineering students.

\section{Conclusions}

Our study suggests that students are more likely to attend workshops that focus on topics of immediate relevance to them, are brought to "their" spaces (like departmental buildings), are advertised directly to them using "push" advertising techniques, and are specific to their needs or the needs of their closest academic peers. Adjusting programming practices to reflect an apparent desire among students for focused and individualized help (even in a group setting) is recommended, though we caution that all practices should be considered in their current local contexts and should not necessarily be changed based on the conclusions of our study alone. 


\section{APPENDIX A}

Note: Below is a print-adapted version of the second survey distributed for this study. The survey was dynamic and distributed using LimeSurvey software and could not be exactly replicated for inclusion in this appendix. The questions and content of the survey should not have been negatively impacted by its adaptation; however, the format and exact presentation has been altered.

\section{Survey on Workshop Failures (and Successes)}

\section{About This Research}

In response to declining attendance at library and student help workshops, this research is aimed at determining what we, as providers, can do to encourage students to attend the sessions we host.

\section{The Survey}

In this 7- to 10-minute survey, please provide details about one specific workshop that you have offered. We are equally interested in workshops that have had both high and low attendance rates, and we encourage you to share any information you are willing to help inform our research. If you have hosted multiple workshops at your institution, we further encourage you to complete the survey more than once; there is no limit to the number of times you may complete the survey.

\section{Incentive}

To thank you for your participation, you can choose to be entered for a chance to win a $\$ 100$ (CAD or equivalent) gift certificate to Amazon, Chapters/Barnes \& Noble, Starbucks, or Tim Hortons. Other gift certificate locations may be considered at the winners' requests.

\section{Eligibility Criteria}

For the purposes of this project, a nonmandatory academic enrichment workshop is defined as any optional, classlike offering provided by a nonprofessor/instructor (such as a librarian, library staff, or staff member at a writing or math help centre) outside of course hours for the purpose of providing academic support. For example, a nonmandatory academic enrichment workshop might be a session on plagiarism, a workshop on GIS software, or a talk about scholarly publishing. Nonmandatory academic enrichment workshops do not include anything offered by a teaching assistant for the purposes of a specific course and do not include any sessions targeted solely at faculty and staff (mixed target audiences welcome).

This project has been reviewed by the Research Ethics Board of the University of New Brunswick and is on file as REB \#2018-019.

There are 21 questions in this survey.

\section{Context}

Please answer all questions in this survey to the best of your knowledge/recollection. If you are uncertain of an answer, please give your best estimate or leave the question blank.

\section{Approximately how many students (FTE) attend your college/university?}

What type of unit do you work in? 
$\square$ Library

$\square$ Other:

$\square \quad$ No answer

Session

What was the advertised title of your session?

What was your session about?

口 General library orientation

$\square$ Searching skills

Citation management software (such as Zotero, RefWorks, and the like)

$\square \quad$ Writing and study skills

$\square$ Academic integrity/plagiarism

$\square$ Course/assignment-specific help

$\square$ Other:

$\square \quad$ No answer

How long was your session (in minutes)?

Which of the following best describes the pedagogy of your session?

$\square$ Lecture

Workshop (with some hands-on component)

Question \& Answer

$\square$ Other:

$\square \quad$ No answer

In which month was your session held?

$\square$ January

$\square$ February

口 March

$\square$ April

$\square$ May

$\square$ June

July

$\square$ August

$\square$ September

口 October

$\square \quad$ November

$\square$ December

What time of day did your session start?

․ Morning (before 11:00 AM)

$\square \quad$ Midday (11:00 AM-2:00 PM)

Afternoon (2:00 PM-5:00 PM)

口 Evening (at or after 5:00 PM)

Where did your workshop take place?

$\square \quad$ In the library

口 In a faculty or departmental building

$\square \quad$ In a university/college residence

$\square$ Other: 
$\square \quad$ No answer

How frequently was your session offered?

Note: Select the option that most closely reflects your session

$\square \quad$ It was the first time it had been offered

$\square \quad$ It has been offered before, but less than once per year

$\square \quad$ It has been offered annually

$\square \quad$ It has been offered twice annually

$\square \quad$ It was part of a new series

$\square \quad$ It was part of a series that has run before

$\square$ Other:

$\square \quad$ No answer

Who was your target audience?

$\square \quad$ All students, staff, and faculty

$\square \quad$ All students

$\square \quad$ All undergraduate students

$\square \quad$ All graduate students

$\square$ Other:

$\square \quad$ No answer

How many attendees did you have?

Promotion and Advertising

Did any units or departments (outside of your own) help you promote your session?

Yes

$\square$ No

口 No answer

If "yes":

Who contributed? Check any that apply

口 Faculty/department

$\square$ Student support/services

$\square$ Library

Other:

How did they contribute? Check any that apply

$\square$ Post on their social media

$\square$ Post on their website

$\square \quad$ Email to their students

$\square$ Digital posters (in other words, LCD screens)

$\square$ Discussed in class

$\square$ Printed posters in their building

$\square$ Other:

What forms of advertising did you make use of? Check any that apply

- Post on your unit's social media

- Post on your unit's website

Digital posters (as on LCD screens)

$\square \quad$ Printed posters in your building or others'

$\checkmark$ Other: 
Did you offer any incentives to draw your target audience to your session? If yes, please indicate what incentive you offered.

$\square$ Yes

Comment:

口 No

$\square \quad$ No answer

Are you aware of any other factors that would/did influence attendance at your session? If yes, please indicate what it was.

口 Yes

Comment:

No

$\square \quad$ No answer

Closing

Do you have any final comments about your workshop that you feel offers insight into your attendance rates? If so, please make them here.

If you wish to be entered into the draw for a $\$ 100$ gift card, or if you wish to receive a summary of the research findings at the end of this study, please indicate your preferences by checking the appropriate box(es) and write your email address in the comments box. Your email address will only be used for the purpose(s) you have indicated.

- I would like to be entered into the draw for a $\$ 100$ gift card.

I would like to receive a summary of the results at the end of this study.

Email address (if applicable): 


\section{Appendix B}

\begin{tabular}{|c|c|c|c|c|c|}
\hline Duration (Range) & $\mathbf{N}$ & \% Successful & Month of Term & $\mathbf{N}$ & \% Successful \\
\hline 30 minutes or less & 25 & $44 \%$ & First & 46 & $61 \%$ \\
\hline $30-60$ minutes & 141 & $56 \%$ & Second & 87 & $59 \%$ \\
\hline 60-90 minutes & 25 & $60 \%$ & Third & 50 & $52 \%$ \\
\hline 90 minutes or more & 26 & $77 \%$ & Fourth & 18 & $61 \%$ \\
\hline \multirow[t]{2}{*}{ (no answer) } & 1 & - & Summer & 11 & $55 \%$ \\
\hline & & & (no answer) & 6 & - \\
\hline Time of Day & $\mathbf{N}$ & $\%$ Successful & Target Audience & $\mathbf{N}$ & \% Successful \\
\hline Before 11:00 AM & 24 & $75 \%$ & All undergraduate students & 35 & $54 \%$ \\
\hline 11:00 AM-2:00 PM & 67 & $60 \%$ & All graduate students & 29 & $52 \%$ \\
\hline 2:00 PM-5:00 PM & 81 & $52 \%$ & All students & 50 & $54 \%$ \\
\hline At or after 5:00 PM & 30 & $63 \%$ & All students, staff, and faculty & 65 & $52 \%$ \\
\hline \multirow[t]{2}{*}{ (no answer) } & 16 & - & Specific group & 37 & $78 \%$ \\
\hline & & & (no answer) & 2 & - \\
\hline Part of a Series & $\mathbf{N}$ & \% Successful & Buy-In & $\mathbf{N}$ & $\%$ Successful \\
\hline Standalone workshop & 162 & $58 \%$ & No faculty support & 92 & $53 \%$ \\
\hline \multirow[t]{2}{*}{ Part of a series } & 56 & $57 \%$ & Faculty support & 79 & $67 \%$ \\
\hline & & & (no answer) & 47 & $51 \%$ \\
\hline Incentive & $\mathbf{N}$ & \% Successful & & & \\
\hline Credit & 22 & $68 \%$ & & & \\
\hline Food/prize & 36 & $52 \%$ & & & \\
\hline None & 160 & $58 \%$ & & & \\
\hline
\end{tabular}

Table: the success rate of workshops within each of the nonsignificant factors is provided with each variable's associated sample size (N).

\section{Notes}

1. Bonnie L. Fong et al., "Assessing and Serving the Workshop Needs of Graduate Students," Journal of Academic Librarianship 42, no. 5 (September 1, 2016): 569-80, https://doi.org/10.1016/j.acalib.2016.06.003; Beth Roszkowski and Gretchen Reynolds, "Assessing, Analyzing, and Adapting: Improving a Graduate Student Instruction Program Through Needs Assessment," Behavioral \& Social Sciences Librarian 32, no. 4 (October 1, 2013): 224-39, https:// doi.org/10.1080/01639269.2013.837798; Lori Critz et al., "Development of the Graduate Library User Education Series," Reference Services Review 40, no. 4 (November 9, 2012): 530-42, https://doi.org/10.1108/00907321211277341.

2. Melissa Bowles-Terry, "Library Instruction and Academic Success: A Mixed-Methods Assessment of a Library Instruction Program," Evidence Based Library and Information Practice 7, no. 1 (2012): 82-95, https://doi. org/10.18438/B8PS4D.

3. Jason Vance, Rachel Kirk, Justin Gardner, and Middle Tennessee State University, "Measuring the Impact of Library Instruction on Freshmen Success and Persistence: A Quantitative Analysis," Communications in Information Literacy 6, no. 1 (2012): 49-58, https://doi.org/10.15760/comminfolit.2012.6.1.117.

4. Tom Rosman, Anne-Kathrin Mayer, and Günter Krampen, "A Longitudinal Study on Information-Seeking 
Knowledge in Psychology Undergraduates: Exploring the Role of Information Literacy Instruction and Working Memory Capacity," Computers \& Education 96 (2016): 94-108, https://doi.org/10.1016/j.compedu.2016.02.011.

5. Joni Blake et al., "The Impact of Information Literacy Instruction on Student Success: A Multi-Institutional Investigation and Analysis," Central University Libraries Research 13 (2017): 1-27.

6. Francesca Marineo and Qingmin Shi, "Supporting Student Success in the First-Year Experience: Library Instruction in the Learning Management System," Journal of Library \& Information Services in Distance Learning 13, no. 1/2 (2019): 40-55, https://doi.org/10.1080/1533290X.2018.1499235.

7. Janet Webster and Loretta Rielly, "A Library Instruction Case Study: Measuring Success from Multiple Perspectives," Research Strategies 19, no. 1 (December 2003): 16-32.

8. Blake et al., "The Impact of Information Literacy Instruction on Student Success"; Vance et al., "Measuring the Impact of Library Instruction on Freshmen Success and Persistence"; Bowles-Terry, "Library Instruction and Academic Success."

9. Webster and Rielly, "A Library Instruction Case Study"; Fong et al., "Assessing and Serving the Workshop Needs of Graduate Students"; Kristin Hoffman et al., "Library Research Skills: A Needs Assessment for Graduate Student Workshops," Issues in Science and Technology Librarianship (2008), https://doi.org/10.5062/f48p5xfc; Critz et al., "Development of the Graduate Library User Education Series"; Roszkowski and Reynolds, "Assessing, Analyzing, and Adapting."

10. Rosman, Mayer, and Krampen, "A Longitudinal Study on Information-Seeking Knowledge in Psychology Undergraduates."

11. Cormac Breen, Mark Prendergast, and Michael Carr, "Investigating the Engagement of Mature Students with Mathematics Learning Support," Teaching Mathematics and Its Applications 34, no. 1 (2015): 16-25.

12. Webster and Rielly, "A Library Instruction Case Study."

13. Juan Gabriel Berumen, Desiree D. Zerquera, and Joshua S. Smith, "More Than Access: The Role of Support Services in the Transitional Experiences of Underrepresented Students in a Statewide Access Program," Journal of Student Financial Aid 45, no. 1 (2015): 27-44.

14. Kathy Booth et al, "Using Student Voices to Redefine Success: What Community College Students Say Institutions, Instructors and Others Can Do to Help Them Succeed," Research and Planning Group for California Community Colleges (2013), http://rpgroup.org.

15. Berumen et al., "More Than Access."

16. Booth et al., "Using Student Voices to Redefine Success."

17. Blake et al., "The Impact of Information Literacy Instruction on Student Success."

18. Peter Copeman and Polly Keightley, "Academic Skills Rovers: A Just in Time Peer Support Initiative for Academic Skills and Literacy Development," Journal of Peer Learning 7 (2014): 1-22.

19. Fong et al., "Assessing and Serving the Workshop Needs of Graduate Students"; Hoffman et al., "Library Research Skills"; Roszkowski and Reynolds, "Assessing, Analyzing, and Adapting."

20. Stephen Cheng and Susan Johnston, "Participation in Peer-Led Academic Support Services: One Adaptation of a Natural Sciences Peer Learning Model to Enrichment in the Humanities," Journal of Peer Learning 7 (2014): 25.

21. Critz et al., "Development of the Graduate Library User Education Series."

22. Erica Litke, "After the Bell Rings: Student Perceptions of After-School," Teachers College Record 111, no. 8 (2009): 1954-1970.

23. Bowles-Terry, "Library Instruction and Academic Success"; Vance et al., "Measuring the Impact of Library Instruction on Freshmen Success and Persistence"; Rosman, Mayer, and Krampen, "A Longitudinal Study on Information-Seeking Knowledge in Psychology Undergraduates"; Blake et al., "The Impact of Information Literacy Instruction on Student Success"; Marineo and Shi, "Supporting Student Success in the First-Year Experience"; Webster and Rielly, "A Library Instruction Case Study."

24. Berumen, Zerquera, and Smith, "More Than Access"; Blake et al., "The Impact of Information Literacy Instruction on Student Success"; Booth et al., "Using Student Voices to Redefine Success"; Fong et al., "Assessing and Serving the Workshop Needs of Graduate Students."

25. Cheng and Johnston, "Participation in Peer-Led Academic Support Services"; Critz et al., "Development of the Graduate Library User Education Series." 